\title{
Rüzgar Türbinleri için Kanat Profillerinin Sayısal Olarak Test Edilmesi
}

\author{
H. DÜZ \\ Otomotiv Mühendisliği, Batman Üniversitesi
}

Geliş Tarihi: 2016-05-07 Kabul Tarihi: 2016-07-02

\section{$\ddot{O} \mathbf{z}$}

Daha verimli rüzgar türbinleri oluşturmak için farklı kanatçık ailesinden beş kanat profili seçilmiştir. Seçilen bu kanatlar farklı hücum açılarında $\left(0^{\circ}, 5^{\circ}, 10^{\circ}, 15^{\circ}\right.$ ve $\left.20^{\circ}\right)$ ve farklı rüzgar hızlarında $(4,7,12$ ve $20 \mathrm{~m} / \mathrm{s}) \mathrm{sayısal}$ olarak test edilmişlerdir. Burada amaç rüzgar türbininin verimi üzerinde doğrudan etkili olan kanat performansını ölçmektedir. Genel olarak bir kanadın performansı $C_{L} / C_{D}$ oranı ile ölçülmektedir. Burada $C_{L}$ kaldırma kuvveti katsayısı ve $C_{D}$ ise sürükleme kuvveti katsayısıdır. Sayısal çalışmadan elde edilen $C_{L} / C_{D}$ değerleri hücum açısıyla ve serbest akım hızıyla olan değişimleri analiz edilmiştir. Yapılan sayısal analize göre rüzgar hızının artması tüm kanat performanslarını azalan bir eğimle artırmıştır. Kanatlar içerisinde FX 63-137 kanat profili $0 \leq \alpha \leq 15^{\circ}$ hücum açıları arasında en yüksek performansa sahip olmuştur. GOE 795 profili $4^{\circ} \leq \alpha$ $\leq 6^{\circ}$ derece hücum açıları arasında ve EPPLER $5800^{\circ} \leq \alpha \leq 5^{\circ}$ hücum açılarında FX 63-137 ile benzer performans göstermişlerdir. Genel olarak $3^{\circ} \leq \alpha \leq 7^{\circ}$ hücum açıları arasında tüm kanatlarda tüm hız değişimlerinde maksimum performans gözlemlenmiştir.

Anahtar Kelimeler: rüzgar türbini, hücum açısı, kanat profili

\section{Numerical Testing of the Airfoil Profiles for The Wind Turbines}

\author{
H. DÜZ
}

Automotive Engineering, University of Batman

\begin{abstract}
To exist more efficiently wind turbines, five airfoil profiles was selected from different airfoil families. The selected airfoils were tested numerically for the different angles of attack $\left(0^{\circ}, 5^{\circ}, 10^{\circ}, 15^{\circ}\right.$ ve $\left.20^{\circ}\right)$ and different wind velocities $(4,7,12$ ve $20 \mathrm{~m} / \mathrm{s})$. Here the aim was to measure the performance of the airfoils given as $C_{L} / C_{D}$ due to the wind turbine efficiency scaled to directly. Here $C_{L}$ and $C_{D}$ is the lift coefficient and drag coefficient of the airfoil respectively. Values of $\mathrm{C}_{\mathrm{L}} / \mathrm{C}_{\mathrm{D}}$ obtained from the numerical study was analysed for the variations with attack angle and free stream velocity. According to the analysys done, at a given attack angle, the wind velocity increasing has increased the performance of the airfoils in a gradient slow decreasing. Among the airfoil profiles, FX 63-137 airfoil profile has shown higher performance than others for the angles of attacks between $0^{\circ} \leq \alpha \leq$ $15^{\circ}$. GOE 795 profile for the angles of attack between $4^{\circ} \leq \alpha \leq 6^{\circ}$ and EPPLER 580 for the angles of attack between $0^{\circ} \leq \alpha \leq 5^{\circ}$ has indicated the similar performance with FX 63-137. In general, maximum performance has been observed in all profiles for the angle of attacks between $3^{\circ} \leq \alpha \leq 7^{\circ}$ in the all velocity variations.
\end{abstract}

Keywords: wind turbine, attack angle, airfoil profile

\section{Giriş}

Gönümüz şartları yaşamı teknolojiye bağımlı hale getirmiştir. İnsan popülasyonun her geçen gün artması ve insan yaşamının daha da rahata kavuşma isteği teknolojinin büyümesine ve dolayısıyla enerjiye olan talebin her geçen gün artmasına neden olmuştur. Bugün enerjinin çok büyük kısmı fosil yakıtlardan karşılanmaktadır. Fosil yakıt rezervleri ise sınırlıdır ve ömürleri bu hızdaki tüketimle kısa olacağı öngörülmektedir. Yakıt tüketimlerinde yayılan egzoz gazları hem çevreye zarar vermekte hem de küresel 1sınma gibi ciddi problemler yaratmaktadır. Gelecekte bu tür problemlerin yaşanmaması ve enerjinin garanti altına alınması için yenilenebilir enerji kaynaklarının hayata geçirilmesi bir zorunluluk haline gelmiştir. Bugün yenilenebilir enerji kaynakları bazı gelişmiş 
ülkelerde hayata geçirilmiş olup enerjinin bir kısmını karşılar durumdadır. Rüzgar, güneş, dalga ve bio-kütle gibi enerjiler bugün önemli yenilenebilir enerji kaynakları arasında sayılmaktadır. Bunlardan Rüzgar enerjisi yararlanılabilen en büyük enerji kaynağı olmuştur. Bugün Almanya, Amerika ve Çin başta olmak üzere sahalara yayılmış büyük güçlü rüzgar türbinleri ile rüzgar enerjisinden yararlanmaktadirlar.

Rüzgar enerjisinden yararlanma tamamıla kanat geometrisine bağlıdır. $\mathrm{Bu}$ nedenle uçaklarda kullanılan kanat profilleri rüzgar türbinlerinin geliştirilmesinde önemli bir etkiye sahip olmuştur. $\mathrm{Bu}$ kanat profilleri farklı hava hılarında ve farklı hücum açılarında farklı performans eğrileri gösterebilmektedir. Kullanılan amaca göre kanat profilleri rüzgar tünellerinde test edilerek performansları ölçülebilmektedir. Rüzgarın farklı hızlarda ve farklı açılarda esmesi kanat performanslarını etkilediğinden her durumda en iyi performans1 gösterecek bir kanat profili bulmak hemen hemen imkansızdır. Farklı uygulamalar için pek çok rüzgar türbini kanadı oluşturulmasına rağmen daha yüksek verimli rüzgar türbinleri oluşturmak amacıyla yeni kanat profillerinin araştırılması gerektiği görülebilmektedir.

Rüzgar türbini kanatlarının gelişimi daha çok uçak kanat profili serileri üzerine kuruludur. örneğin NACA230, NACA44, NACA63-2, NACALS ve FX kanatları bunlardan birkaçı sayılır. Bunlardan başka rüzgar türbinleri için özel oluşturulmuş bazı kanatlar vardır. Örneğin NRELS serili kanatlar Amerikalılar tarafindan, DU serili kanatlar Almanlar tarafindan, RISO serili kanatlar ise danimarkalılar tarafından ve FFA-W serili kanatlar ise isveçliler tarafından dizayn edilmiş özel kanatlardır [12].

Bir kanat profilinin performansı genelde kaldırma kuvveti katsayısı $\left(C_{L}\right)$ ve sürükleme kuvveti katsayısına $\left(\mathrm{C}_{\mathrm{D}}\right)$ oranı ile ölçülmektedir. Temel hedef kaldırma kuvveti katsayısının yüksek ve sürükleme kuvveti katsayısının da düşük olmasıdır. Şimdiye kadar kanat profilleri ile ilgili yapılan sayısal veya deneysel çalışmalar üç kısma ayrılabilir. İlki belli bir amaç doğrultusunda kanat profillerinin performanslarının araştırılması ikincisi ise belirli bir kanat profili üzerinden türbülans modellerinin test edilmesi ve geliştirilmesi üçüncüsü ise farklı kanat geometrileri tasarlamak için matematiksel algoritmaların ve modellerin test edilmesi ve karşılaştırılmasıdır.

Bunlardan, ilk gruba birçok örnek verilebilir. Selig ve Granahan [7] mesken yerlere yakın kurulabilecek sessiz ve verimli küçük rüzgar türbinleri geliştirmek amacıyla farklı kanat profili ailesinden seçilmiş E387, S822, SD2030, FX63-137, S834 ve SH3055 kanat profillerini aerodinamik ve aeroakustik yönünden rüzgar tünelinde test etmişlerdir. Parezanovic ve diğerleri [11] rüzgar türbinleri için yeni kanat profilleri tasarlamak amaciyla NACA 63(2)215, FFA-W3211 ve A-AIRFOIL kanat profillerinin performanslarını incelemişlerdir. Tangler ve Somers ise [13] bir şekilde yatay eksenli rüzgar türbinleri için NREL serisi kanat profilleri üzerinde performans analizleri yapmışlardır. Geissler [4] yapmış olduğu sayısal çalışmada NLR 7301 kanat profili üzerindeki transonik akışın titreşim etkisini Spalart-Allmaras türbülans modeli kullanarak incelemiştir. Güleren ve Demir [6] rüzgar türbinleri için yeni profil tasarlamak amacıyla EPPLER 625, EPPLER 664, CLARK Y, Eiffel 10 (Wright), FX 69-PR-281 ve NACA Munk M-4 kanat profillerini yüksek Reynolds sayısında ve düşük hücum açılarında $\left(0^{\circ} \leq \alpha \leq 20^{\circ}\right) \mathrm{CL}-\alpha$ ve $\mathrm{C}_{\mathrm{L}} / \mathrm{C}_{\mathrm{D}}-\alpha$ değişimleri yönünden sayısal olarak incelemişlerdir. Sayısal çalışmalarında SpalartAllmaras (SA) türbülans modelini kullanmışlardır.

İkinci grupta ise kanat profili üzerindeki akışta türbülans modellerini test etme ve geliştirme vardır. Örneğin Costa Rocha ve diğerler [10] $k-$ omega SST türbülans modelini türbülans modelleme sabiti $\beta^{\prime}$ nın birkaç değeriyle özellikle sürükleme katsayısı üzerinden kalibre etmişlerdir. Amanullah ve diğerleri [1] düşük Reynolds sayılı ve yüksek türbülans yoğunluklu akışlarda akış ayrılmasının etkisini ve karakteristiğini daha iyi kavramak için ince simetrik NACA0021 kanadı etrafındaki akış olayını yeni geçiş akışı tahmin modelleri olan $\gamma-R e_{\theta}$ tabanlı bağıntı ve laminar kinetik enerji $\kappa-\kappa_{L}-\omega$ modellerinin kullanarak sayısal olarak incelemişlerdir. Sonuçta $\kappa-\kappa_{L^{-}}$ $\omega$ modelin akış ayrılma ve tekrar birleşme akış olayını daha iyi tahmin ettiği görülmüştür. Zhang ve diğerleri [14] kanat geometrilerinin akış ayrılması ve laminar türbülans geçiş akışına etkisini araştırmak için 10 derece hücum açısında ve $R e=10^{4}$ Reynolds say 1 sinda NACA-4412 ve NACA-0012-64 kanatları üzerindeki sıkıştırılamaz akışta direk sayısal benzetim (DNS) gerçekleştirmişlerdir. Martinat ve diğerleri [8] URANS tekniğini NACA 0012 profili üzerine denemişlerdir. Bertagnolio ve diğerleri [2] rüzgar türbin kanatları için RISO-B1-18 kanat profili çevresindeki akışı Ayrılmış Eddy Benzetimi (LES) ile incelemişlerdir. Nicolas ve diğerleri [9] türbülanslı kanat akışlarını çözmek için duvara yakın ağın yeterince iyileşmesini sağlayan lattice Boltzmann metoduna dayalı bir metodoloji önermişlerdir. 
Üçüncü grup ise kanat geometrilerinin tasarlanması ve modellenmesini içermektedir. Quan ve diğerleri [12] orta kalınlıktaki rüzgar türbini kanatları için kanat integral yöntemi ve B-spline eğri metodunu birleştirerek yeni bir dizayn metodu geliştirmişlerdir. Bu yeni dizayn metodunun diğer standart metodlara göre daha iyi sonuçlar ürettiği aynı zamanda farklı kalınlıktaki kanatlar içinde kullanılabileceği ve bu yüzden rüzgar türbin kanadını optimize etmek için seçilebilir yeni bir metod olduğunu göstermişlerdir. Dongli ve diğerleri [3] yüksek irtifada düşük hızda seyreden uçak kanatları için bağıl kalınlığın kanat performansına olan etkisini $5 \times 10^{5}$ gibi bir Reynolds sayılı akış için sayısal olarak incelemişlerdir. Sonuçta, stall kontrolü ve iyi kanat performansı sağlamak için maksimum bağıl kalınlık değerinin olabildiğince küçük ve konumunun da firar kenarına yakın olması gerektiğini çalışmalarında belirtmişlerdir.

Heyong ve diğerleri [5] co-flow jet (kanatta üfleme-emme) olarak belirtilen bir aktif akış kontrol metodunu S809 rüzgar türbini kanadına uygulayarak simule etmişlerdir. Sonuçta bu akış kontrol metodunun akış ayrılmasını kontrol ederek kanat performansını artırmada önemli bir etkiye sahip olduğunu ve gelecek rüzgar türbin kanatları için etkili ve vaat veren aktif bir akış kontrol metodu olduğunu bildirmişlerdir.

Yukarıda verilen çalışmalara ek olarak burada yapılmak istenen rüzgar türbinlerinde kullanılabilecek nitelikte farklı kanatçık ailelerinden seçilmiş kanat profillerinin değişik hücum açılarında ve farklı rüzgar hılarında performanslarının sayısal olarak incelenmesidir. Sayısal sonuçlara güvenilirlik kazandırmak amacıyla çalışmalara ek olarak NACA0012 ve NACA2412 için yayınlanmış deney değerleriyle de sayısal sonuçlar karşılaştırılmıştır.

\section{Sayısal Analiz}

İlk önce NACA0012 ve NACA2412 deney koşulları paralelinde sayısal çözümleme yapılmış ve sonuçlar bunların deney değerleriyle karşılaştırılmıştır. NACA0012 ve NACA2412 kanat profillerinin kartezyen koordinatlardaki iki boyutlu kodlama dataları temin edilmiştir (mselig.ae.illinois.edu). Temin edilen kanat profilleri veter uzunluğu $1 \mathrm{~m}$ olan modellerdir. Şekil 1 kanat profilinin geometrisi ve onu tanımlayan terimleri içermektedir. Şekil 1'de gösterildiği gibi veter uzunluğu hücum kenarını ile firar kenarını birleştiren bir doğrudur. Kamburluk eğrisi ise kanat profilinin alt ve üst yüzey sınırlarına eşit uzaklıkta çizilen eğridir. Burada $\alpha$ hücum açısı ve $\beta$ açısı ise kanat çıkış açısıdır. Maksimum kalınlık kanadın kalınlığ 1 ve maksimum kamburluk ise kamburluk eğrisi ile veter uzunluğu arasındaki kalınlıktır. Şekil 1 'de bu terimlerin geometrideki ifadeleri göstermiştir.

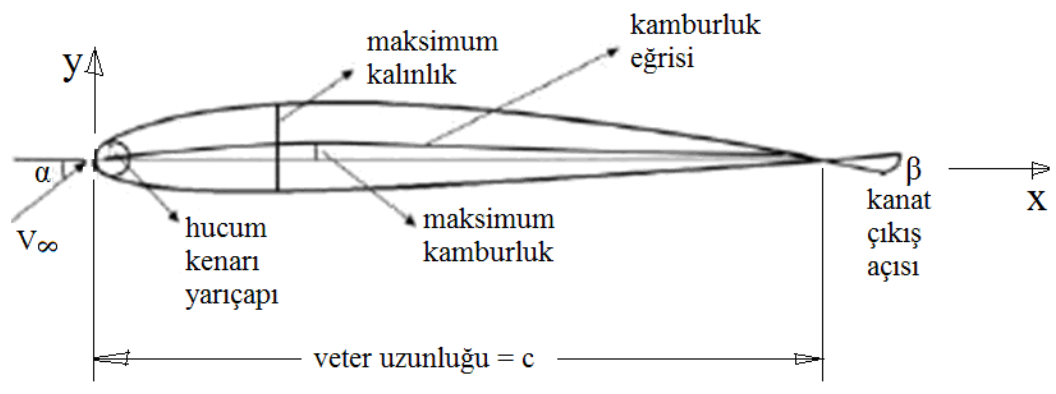

Şekil 1. Kanat geometrisi tanımlama

İlkönce kartezyen koordinatlarda iki boyutlu kanat geometrisi oluşturulmuştur. Daha sonra kanat geometrisini içine alacak şekilde veter uzunluğun 12 katı kadar bir hava akış alanı oluşturulmuştur. Akış alanı dış sınırları kanat etrafında gelişen havanın etkisinin ihmal edilebilir olduğu yeteri kadar bir uzaklığa kadar büyütülmüştür. CFX iki boyutlu çözüm sağlamadığından akış alanı tek ağ hücresi kalınlığında extrude edilerek iki boyutlu çözüm özelliği sağlanmıştır. Katı kanat geometrisi hava akış alanından çıkarılarak ince simetrik bir hava akış hacmi oluşturulmuştur. Hava akışının temas ettiği kanat yüzeyleri hava akış hacminde duvar sınır şartı olarak atanmıştır. Burada kanat etrafindaki havanın üçüncü boyuttaki simetriliğinden yararlanarak iki boyutlu çözüm sağlanmıştır. Şekil 2 kanat etrafındaki hava akış alanını göstermektedir. 


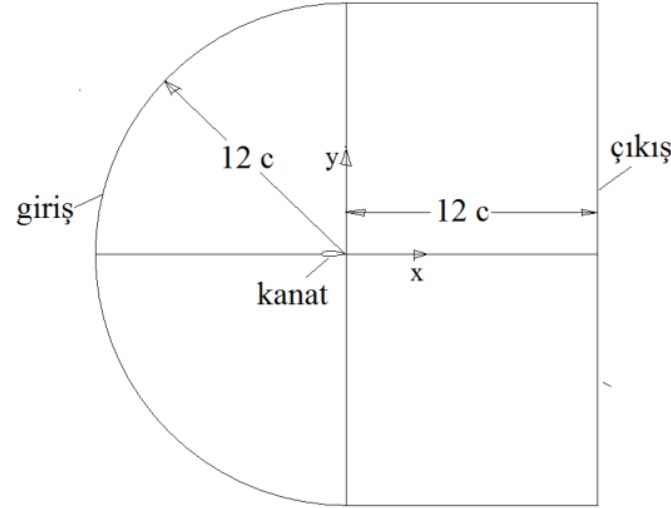

Şekil 2. kanat etrafında hava akış alanı

Oluşturulan akış geometrisi küçük kontrol hacimli elemanlara bölünerek akış alanında ağ oluşturulmuştur. Oluşturulan ağ kanat sınırlarına yakın sıklaştırılmış, sınırlardan uzaklara doğru ise seyrekleştirilmiş̧ir. Bu şekilde ağ eleman sayısı minimum düzeyde tutulmuştur. Kanat etrafinda hız, basınç gibi akış özelliklerinin ağ düğüm noktaları arasında değişimleri yüksek olduğundan bu gibi akış özelliklerinin değişimlerinin yakalanabilmesi için akış gelişmesinin etkili olduğu bölgelerde ağ sıklaştırılmıştır. Bu bölgeler sınır tabakanın geliştiği kanat yüzeyi yakın civarı ve firar kenarı arka akış bölgesidir. Boyutsuz duvar mesafesi $\mathrm{y}^{+}<1$ olacak şekilde kanat civarı etrafinda ağ sıklaş̧ırılmıştır. Şekil 3 'te gösterildiği gibi hücum kenarı çevresi ve kuyruk iz bölgesinde akış özelliklerinin yakalanabilmesi için ağ sıklığı artırılmıştır.

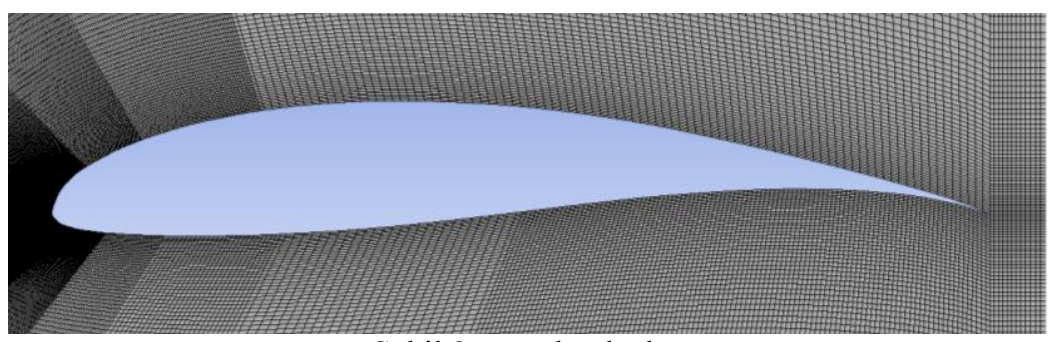

Şekil 3. Yapılandırılmış ağ

Ağdan bağımsız çözüm sağlanıncaya kadar ağ sayıs1 artırılmıştır. Daha sonra sınır şartları, akış özellikleri ve çözücü kontrol ayarları girilmiştir. Giriş sınır şartında hava serbest akım hızında ve düşük türbülans yoğunluklu (1\%) olarak $25{ }^{\circ} \mathrm{C}$ sıcaklıkta akış alanına girmektedir. Farklı hücum açılarında çalışma yapmak için kanat profili açısı değiştirmeye gerek kalmadan, her hücum açısında yeniden ăg oluşturma problemini ortadan kaldırarak, giriş hızı istenilen hücum açısı sağlayacak şekilde akış alanına açılı olarak tanıtılmıştır. Çıkış sınır şartında akış atmosfere açık ve sıfır etkin basınç değeri ile akış alanından ayrılmaktadır. Yan yüzeyler simetrik sınır şartı olarak ve profil sinırları duvar olmak üzere pürüzsüz duvar ve kaymama koşulu ile sınır şartları oluşturulmuştur. Sınır şartlarından giren ve çıkan havanın mutlak basıncı referans basınç olarak 1 atm (101325Pa) basınç değeri girilmiştir. Hava ideal gaz olarak seçilmiştir. Girişte hava akışı daimi akış olarak akış alanına girmektedir. Kanat etrafı akış alanı Reynold Ortalamalı Navier stokes (RANS), süreklilik ve enerji denklemleriyle ayrıklaştırılarak sayısal olarak CFX akış çözücüsü ile çözdürülmüştür.

RANS denklemler anlık akış özelliklerini zaman ortalamalı değerleri üzerinden ișlem yaparak türbülanslı akışları çözen denklemlerdir. Burada akış alanında oluşan ve daimi olmayan türbülans girdaplar daimi bir akış türü haline dönüştürülerek çözüm sağlanır. $\mathrm{Bu}$ nedenle türbülansın oluştuğu akış alanında türbülans çalkantılarının izotropik bir dağılıma ve ölçeklerinin yakın aralıkta olması daimi bir akış alanını oluşması için yeter bir koşul olmaktadır. Kanat etrafinda izotropik olmayan büyük girdapların oluşması durumlarında RANS denklemler daimi akışı oluşturamazlar ve bu da çözümlerde yakınsama problemlerine neden olur. Bunun yerine türbülanslı akış alanı zamana bağlı akış denklemleri ile çözülmelidir. Direkt sayısal benzetim (DNS) ve büyük eddy benzetimi (LES) daimi olmayan türbülanslı akışların çözümü için tercih edilen iki sayısal yöntemdir.

Sıkıştırılamaz, daimi olmayan yatay bir akış türü için $\boldsymbol{x}$ yününde momentum denklemi aşağıdaki gibi olmaktadır.

$\rho\left(\frac{\partial u}{\partial t}+\nabla u(V)\right)=-\frac{\partial P}{\partial x}+\mu \nabla^{2} u-\rho\left(\frac{\partial u^{\prime 2}}{\partial x}+\frac{\partial u^{\prime} v^{\prime}}{\partial y}+\frac{\partial u^{\prime} w^{\prime}}{\partial z}\right)$

zaman ortalamalı $x$ yününde momentum denklemi ise, 
$\rho\left(\frac{\partial \bar{u}}{\partial t}+\nabla \bar{u}(\bar{V})\right)=-\frac{\partial \bar{P}}{\partial x}+\mu \nabla^{2} \bar{u}-\rho\left(\frac{\partial \overline{u^{\prime 2}}}{\partial x}+\frac{\partial \overline{u^{\prime} v^{\prime}}}{\partial y}+\frac{\partial \overline{u^{\prime} w^{\prime}}}{\partial z}\right)$

(2)

yukarıdaki denklemlerde $V$ hız vektörü; $u$ ve $P$ anlık hız ve basınç değerleri; $\bar{u}$ ve $\bar{P}$ zaman ortalamalı hız ve basınç değerleri ve $u^{\prime} v^{\prime} v e w^{\prime}$ sırasıyla $\mathrm{x}, \mathrm{y}, \mathrm{z}$ yününde türbülans hız çalkantı değerleridir. Denklemde türbülans akış etkisini gösteren son terime türbülans gerilmeleri veya Reynolds gerilmeleri denir. Bu nedenle bu son denklem Reynold Ortalamalı Navier Stokes denklemlerinden (RANS) $x$ yünündeki momentum denklemidir.

$$
\tau=-\rho \overline{u^{\prime} v^{\prime}}
$$

RANS Denklemlerde ortalama akış özellikleri bilinirken Reynolds gerilmeler ise bilinmemektedir. $\mathrm{Bu}$ nedenle Reynolds gerilmelerini çözen çeşitli yarı ampirik modeller geliştirilmiştir. Bunlardan önemli birisi de Boussinesq hipotezi ile çözümdür. Bu hipotezin ifadesi

$$
-\rho \overline{u^{\prime} v^{\prime}}=\mu_{t} \frac{\partial \bar{u}}{\partial y}
$$

Bu hipotezde önerilen $\mu_{t}$ türbülans viskozitesi olup değeri deneysel verilere dayanan modellerle çözülür. $\mathrm{Bu}$ nedenle türbülans viskozitesini çözmeye yönelik pek çok türbülans modeli geliştirilmiştir. En yaygın kullanılanlar ise iki denklemli k-epsilon ve k-omega modelleridir. Bu sayısal çalışmada SST k-omega türbülans modeli tercih edilmiştir. Tercihin sebebi ise yüzeyden akış ayrılmaları ve laminar-türbülans geçişlerinin bu modelle iyi tahmin edilmesidir. Model duvara yakın sınır tabaka içerisinde sık ağ gerektirir. Bu nedenle boyutsuz duvar mesafesi $\mathrm{y}^{+}<1$ olacak şekilde duvara yakın ağ oluşturulmalıdır. Türbülans modelinin seçilmesiyle birlikte enerji denklemi de aktif hale getirilmiş̧ir. Enerji denklemi kanat hücum kenarına yaklaşan havanın oluşturduğu durağan basınç, kanat yüzey sürtünmesi ve akış içerisindeki viskoz kuvvetler akış sıcaklığını artırdığından akış boyunca yoğunluğun önemli ölçüde değişmesine neden olur. $\mathrm{Bu}$ nedenle akış alanı çözümünde enerji denklemine ihtiyaç duyulur.

Yakınsama kriteri olarak artarda iki iterasyon arasında mutlak hata değeri $10^{-5}$ 'e varıncaya kadar iterasyonlar devam ettirilmiş ve 300-500 arasında iterasyon sayısı ile çözümler sonlandırılmıştır. Akış alanında ayrıklaştırılmadan oluşan denklemler CFX akış çözücüsüyle çözdürülmüştür.

\section{Kanat Katsayıları ve Deneysel Karşılaştırma}

Sürükleme katsayısı aşağıda gösterildiği gibi kanat yüzeyine etki eden toplam sürtünme ve basınç kuvvetlerinin $x$ yünündeki bileşenlerinin boyutsuzlaştırılmış halini ve kaldırma katsayısı da $y$ yününde oluşan kuvvet bileşenlerinin boyutsuzlaştırılmış halini göstermektedir.

$$
\begin{aligned}
& C_{L}=C_{N} \cos \alpha-C_{A} \sin \alpha \\
& C_{D}=C_{N} \sin \alpha+C_{A} \cos \alpha \\
& C_{p}=\left(\frac{P-P_{\infty}}{P_{d, \infty}}\right)
\end{aligned}
$$

Bu denklemlerde, $\alpha$ hücum açısını, $C_{N}$ kanat profili üzerindeki normal kuvvet katsayısını, $C_{A}$ eksenel yünde kuvvet katsayısını ve $C_{P}$ kanat yüzeyindeki basınç katsayısını göstermektedir. Denklemde, $P$ kanat yüzeyi üzerinde oluşan statik basınc1, $P_{\infty}$ serbest akım statik basıncını, $P_{d, \infty}$ ise serbest akım dinamik basıncını göstermektedir. $C_{N}$ ve $C_{A}$ aşağıda gösterildiği gibi kanat yüzeyi boyunca yerel oluşan basınç ve sürtünme kuvveti katsayılarının integre edilmesiyle oluşmaktadır.

$$
C_{N}=\frac{1}{c}\left[\int_{0}^{c}\left(C_{p, a l t}-C_{p, i \text { ist }}\right) d x+\int_{0}^{c}\left(C_{f, u \text { ist }} \frac{d y_{\text {ist }}}{d x}-C_{f, a l t} \frac{d y_{\text {alt }}}{d x}\right) d x\right]
$$

$C_{A}=\frac{1}{c}\left[\int_{0}^{c}\left(C_{p, \text { ist }} \frac{d y_{\text {üst }}}{d x}-C_{p, a l t} \frac{d y_{\text {alt }}}{d x}\right) d x+\int_{0}^{c}\left(C_{f, \text { üst }}+C_{f, a l t}\right) d x\right]$

Burada $C_{f}$ sürtünme katsayısı olup kanat yüzeyinde oluşan duvar kayma gerilmesinin serbest akım dinamik basıncına oranıdır.

NACA0012 ve NACA2412 profilleriyle yapilan sayısal çalışmalardan elde edilen sürükleme ve kaldırma katsayıları yine aynı profillerin deney değerleriyle karşılaştırılmıştır. Karşılaştırma sonuçları Tablo 1 'de NACA2412 için verilmiştir. Tablo 1 de ayrica Güleren ve Demir 'in NACA2412 ile yaptığı sayısal çalışmalara da yer verilmiştir.

Tablo 1. NACA2412 için deney ve sayısal sonuçların karşılaştırılması 


\begin{tabular}{|c|c|c|c|}
\hline $\begin{array}{c}\text { Hücum açısı } \\
(\boldsymbol{\alpha})\end{array}$ & Deneysel & $\begin{array}{c}\text { GÜLEREN ve DEMİR } \\
\text { (sayısal) }\end{array}$ & $\begin{array}{c}\text { Şimdiki Çalışma } \\
\text { (sayısal) }\end{array}$ \\
\hline$-4^{\circ}$ & -0.2 & $-0,21$ & -0.193 \\
\hline $4^{\circ}$ & 0.65 & 0,66 & 0.652 \\
\hline $12^{\circ}$ & 1.4 & 1,39 & 1,437 \\
\hline $15^{\circ}$ & 1.6 & 1,53 & 1,65 \\
\hline $20^{\circ}$ & 1.2 & - & -- \\
\hline
\end{tabular}

Tablo 1 değerleri incelendiğinde sayısal çalışma değerlerinin deney değerleri ile yakın oldukları görülür. Aynı zamanda çıkarılan sayısal değerler Güleren ve Demir sayısal değerleri ile de tüm hücum açılarında yakın değerlerdedir. Burada sayısal değerler maksimum \%7.8, minimum \%0,3 ve ortalamada \%3.7 sapma miktarı ile deney değerlerine yakınlık sağlamışlardır. Güleren ve Demir çalışmasında olduğu gibi şimdiki çalışmada da 20 derece hücum açısında çözümde yakınsama olmamıştır. Bunun nedeni olarak yüksek hücum açılarında kanat etrafında firar kenarına doğru daimi akış özelliği göstermeyen büyük girdapların oluşması olarak tahmin edilmektedir. Türbülans yapıları arasındaki boyut farkının yüksek olması ve izotropik olmayan dağılım daimi olmayan bir çözümü gerektirir. Bu nedenle 20 derece hücum açısı daimi olmayan bir akış analizini gerektirmiştir. Tablo 1 'de deney değerleriyle görülen uyum sayısal sonuçların güvenilir olduğunu göstermiştir.

Sayısal çalışmanın doğruluğu ayrıca NACA0012 kanat profili için $9 \times 10^{6}$ Reynolds sayısında yayınlanmış deney değerleri ile de test edilmiştir. Deney koşullarıla paralel yapılan sayısal çalışmada kaldırma ve sürükleme katsayıları $\mathrm{C}_{\mathrm{L}}=$ 0.247 ve $C_{D}=0.00796$ olarak bulunmuştur. Çıkarılan bu sayısal değerlerin NACA0012 yayınlanmış deney değerleri olan $C_{L}=0.241$ ve $C_{D}$ $=0.0079$ ile karşılaştırıldığında yakın değerlerde oldukları görülebilmektedir. Şekil 4 'te kanat alt ve üst yüzey için çıkarılan basınç katsayısı yine NACA0012 kanat profili 9x10 yayınlanmış deney değerleri ile de karşılaştırılmıştır.

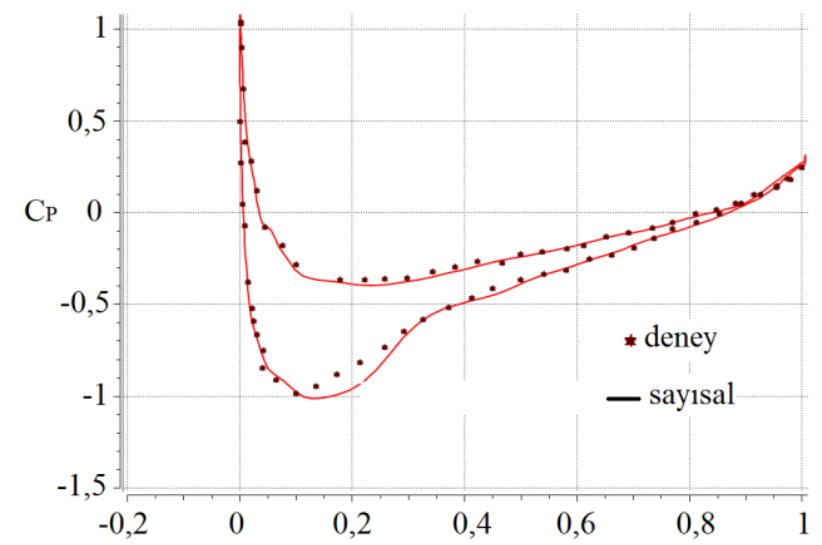

Şekil 4. Sayısal ve deney basınç katsayılarının karşılaştırılması

$\mathrm{Bu}$ karşılaştırmada kanadın alt ve üst yüzeyindeki basınç katsayılarının deney değerleri ile olan çok iyi uyumu sayısal çalışmanın doğruluğunu bir kat daha pekiştirmektedir.

\section{Sayısal Sonuçlar}

Bu kısımda farklı hücum açılarında ve farklı akıș hızlarında yapılan sayısal çalışma sonuçları değerlendirilmiştir. Her kanat profili için sayısal çalışmadan elde edilen $C_{L}, C_{D}, C_{L} / C_{D}$ ve $C_{P}$ değerleri hücum açısı ve serbest akım hızı ile olan değișimleri incelenmiștir. Sayısal çalıșmaya konu olan bu beş kanat profili aşağıda Şekil 5 'te gösterilmiştir.

Şekil 5 te verilen kanat profilleri incelendiğinde maksimum profil kalınlığı en yüksek olan FX 84W-218 iken en ince profil GOE 795 'tir. FX 63-137 ve EPPLER 580 kanatların üst yüzeylerinde tam geometrik benzerlik varken alt yüzeyde ise benzerlik düşük kalmaktadır. Selig S8036 maksimum kalınlığı düşük olmasına rağmen FX 84W-218 ile alt yüzeyde bir geometrik benzerliğe sahiptir.

Tablo 2 'den Tablo 6 'ya kadar verilen tablolar sirasiyla FX 84-W-218, Selig S8036, FX-63-137, EPPLER 58 ve GOE 795 kanat profilleri için sayısal $C_{L}$ ve $C_{D}$ değerlerini vermiştir. Tablolarda verilen sayısal değerler incelendiğinde $C_{L}$ değerlerinin hücum açısının artmasıyla birlikte arttığı ve aynı zamanda verilen bir hücum açısı için 
de hız değerlerinin artmasıyla da $C_{L}$ değerlerinin de arttığı görülmektedir. $C_{D}$ değerleri de ayrıca incelendiğinde hücum açısının artmasıyla arttıkları fakat verilen bir hücum açısında ise hız değerlerinin artmasıyla azaldıkları görülmektedir.

Hızın artmasıyla $C_{D}$ deki bu değer azalmasının sebepleri olarak şunlar gösterilebilir. Serbest akım hızının artmasıyla birlikte $C_{L}$ değerlerinin artması alt ve üst yüzey arasındaki basınç farkının artması ile ilişkilidir. $\mathrm{Bu}$ nedenle düşey yünde kuvvet bileşenlerinin artması eksenel yünde sürükleme kuvvetinin azalmasına neden olabilir. Profil üst yüzeyde firar kenarına doğru basıncın artması, kanat yüzeyine etki eden basınç kuvvetlerinin eksenel yündeki bileşeninin sürükleme kuvvetine tersi yünde etki etmesi sürükleme kuvvetini serbest akım hızının artmasıyla daha da güçlü bir şekilde düşürmesi olarak görülebilir.
FX 84-W-218

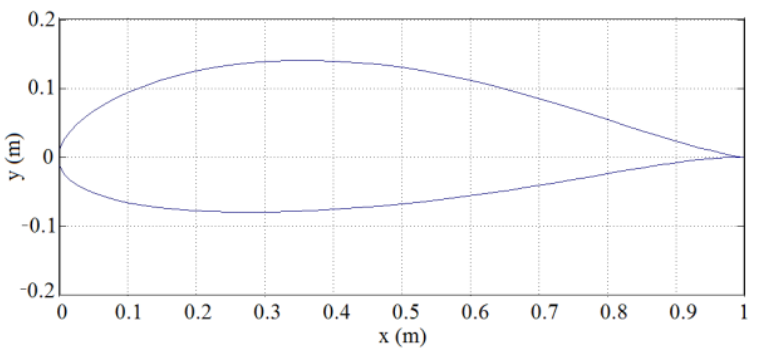

FX 63-137

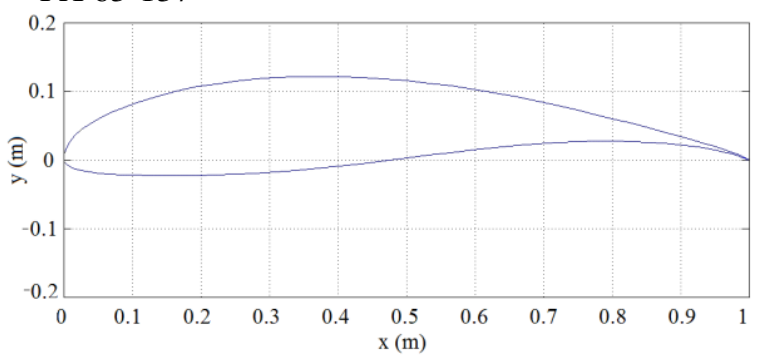

GOE 795

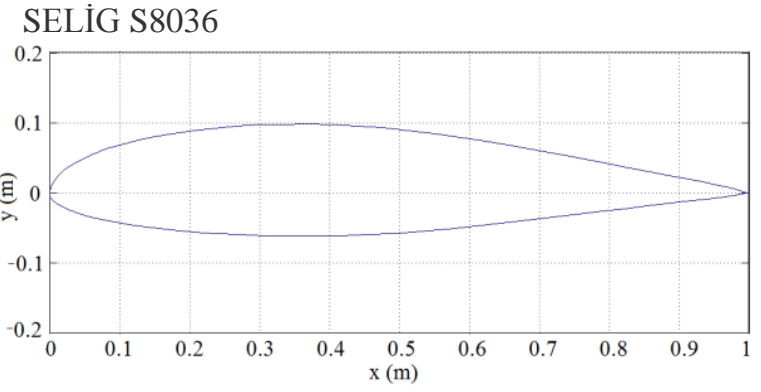

EPPLER 580

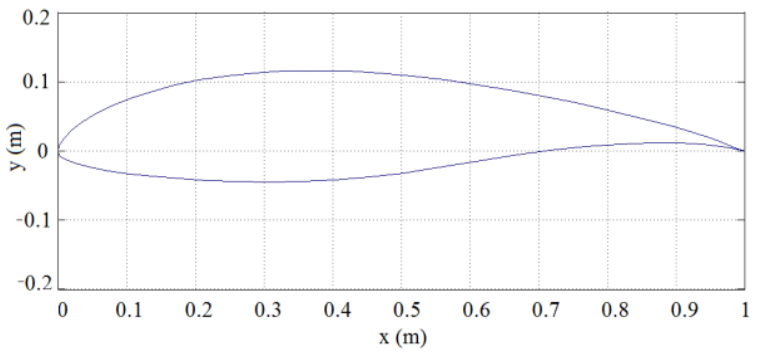

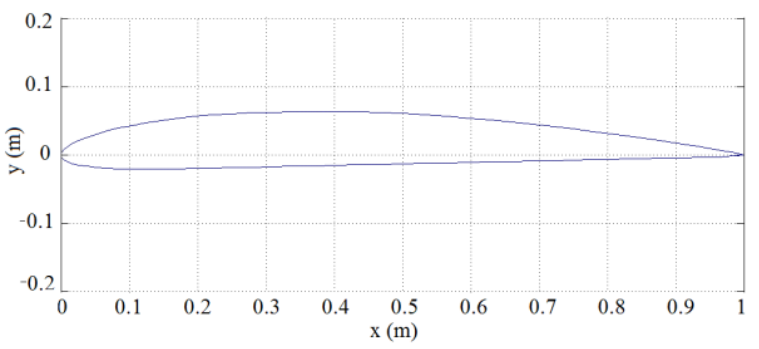

Şekil 5. Kanat profillerinin iki boyutlu kartezyen gösterimi

Tablo 2. FX 84-W-218 için $\mathrm{C}_{\mathrm{L}}$ ve $\mathrm{C}_{\mathrm{D}}$ değerleri

\begin{tabular}{|c|c|c|c|c|c|c|}
\hline \multicolumn{7}{|c|}{ FX 84-W-218 } \\
\hline & $\mathbf{V}(\mathbf{m} / \mathbf{s})$ & $\mathbf{0}^{\mathbf{o}}$ & $\mathbf{5}^{\mathbf{0}}$ & $\mathbf{1 0}^{\mathbf{o}}$ & $\mathbf{1 5}^{\mathbf{0}}$ & $\mathbf{2 0}^{\mathbf{0}}$ \\
\hline \multirow{3}{*}{$\mathbf{C}_{\mathbf{L}}$} & $\mathbf{4}$ & 0,247 & 0,69 & 1,026 & 1,202 & ------ \\
\cline { 2 - 8 } & $\mathbf{7}$ & 0,279 & 0,754 & 1,114 & 1,311 & ------ \\
\cline { 2 - 8 } & $\mathbf{1 2}$ & 0,29 & 0,788 & 1,179 & 1,403 & ------ \\
\hline
\end{tabular}

\begin{tabular}{|c|c|c|c|c|c|c|} 
& $\mathbf{2 0}$ & 0,302 & 0,815 & 1,228 & 1,475 & ----- \\
\hline \multirow{4}{*}{$\mathbf{C D}_{\mathbf{D}}$} & $\mathbf{4}$ & 0,0184 & 0,0258 & 0,044 & 0,0769 & ----- \\
\cline { 2 - 8 } & $\mathbf{7}$ & 0,01558 & 0,0225 & 0,0385 & 0,0677 & ----- \\
\cline { 2 - 8 } & $\mathbf{1 2}$ & 0,0144 & 0,0206 & 0,0348 & 0,0629 & ----- \\
\cline { 2 - 8 } & $\mathbf{2 0}$ & 0,0133 & 0,0193 & 0,0324 & 0,0568 & ----- \\
\hline
\end{tabular}


Tablo 3. selig S8036 için $C_{L}$ ve $C_{D}$ değerleri

\begin{tabular}{|c|c|c|c|c|c|c|}
\hline \multicolumn{7}{|c|}{ selig S8036 } \\
\hline & $\mathbf{V}(\mathbf{m} / \mathbf{s})$ & $\mathbf{0}^{\mathbf{o}}$ & $5^{\circ}$ & $10^{\circ}$ & $15^{\circ}$ & $20^{\circ}$ \\
\hline \multirow{4}{*}{$\mathbf{C}_{\mathbf{L}}$} & 4 & 0,136 & 0,606 & 1,016 & ------- & ------- \\
\hline & 7 & 0,143 & 0,625 & 1,059 & ------- & ------- \\
\hline & 12 & 0,149 & 0,639 & 1,082 & -------- & ------- \\
\hline & 20 & 0,155 & 0,649 & 1,102 & & \\
\hline \multirow{4}{*}{$C_{D}$} & 4 & 0,0153 & 0,0194 & 0,0313 & ------- & ---- \\
\hline & 7 & 0,0137 & 0,0175 & 0,028 & ------- & \\
\hline & 12 & 0,0124 & 0,0162 & 0,0268 & - & ------- \\
\hline & 20 & 0,0114 & 0,0153 & 0,0257 & |----- & --.--- \\
\hline
\end{tabular}

Tablo 4. FX-63-137 için $\mathrm{C}_{\mathrm{L}}$ ve $\mathrm{C}_{\mathrm{D}}$ değerleri

\begin{tabular}{|c|c|c|c|c|c|c|}
\hline \multicolumn{7}{|c|}{ FX-63-137 } \\
\hline & $\mathbf{V}(\mathbf{m} / \mathbf{s})$ & $\mathbf{0}^{\mathbf{o}}$ & $\mathbf{5}^{\mathbf{0}}$ & $\mathbf{1 0}^{\mathbf{o}}$ & $\mathbf{1 5}^{\mathbf{0}}$ & $\mathbf{2 0}^{\mathbf{0}}$ \\
\hline \multirow{5}{*}{$\mathbf{C}_{\mathbf{L}}$} & $\mathbf{4}$ & 0,803 & 1,328 & 1,753 & 1,889 & ------ \\
\cline { 2 - 8 } & $\mathbf{7}$ & 0,819 & 1,354 & 1,803 & 2,049 & ------ \\
\cline { 2 - 8 } & $\mathbf{1 2}$ & 0,833 & 1,375 & 1,846 & 2,144 & ------ \\
\hline & $\mathbf{2 0}$ & 0,846 & 1,397 & 1,889 & 2,228 & ------ \\
\hline \multirow{4}{*}{$\mathbf{C}_{\mathbf{D}}$} & $\mathbf{4}$ & 0,0182 & 0,0257 & 0,0384 & 0,0336 & ------ \\
\cline { 2 - 8 } & $\mathbf{7}$ & 0,0176 & 0,02504 & 0,0367 & 0,0582 & ------ \\
\cline { 2 - 8 } & $\mathbf{1 2}$ & 0,0169 & 0,0243 & 0,0353 & 0,0537 & ------ \\
\hline & $\mathbf{2 0}$ & 0,0162 & 0,0231 & 0,0336 & 0,0489 & ------ \\
\hline
\end{tabular}

Tablo 5. EPPLER 58 için $\mathrm{C}_{\mathrm{L}}$ ve $\mathrm{C}_{\mathrm{D}}$ değerleri

\begin{tabular}{|c|c|c|c|c|c|c|}
\hline \multicolumn{7}{|c|}{ EPPLER 58} \\
\hline & $\mathbf{V}(\mathbf{m} / \mathbf{s})$ & $\mathbf{0}^{\mathbf{o}}$ & $5^{0}$ & $10^{\circ}$ & $15^{\circ}$ & $20^{\circ}$ \\
\hline \multirow{4}{*}{$\mathbf{C}_{\mathbf{L}}$} & 4 & 0,828 & 1,309 & 1,566 & ------- & -------- \\
\hline & 7 & 0,848 & 1,335 & 1,602 & ------- & -------- \\
\hline & 12 & 0,863 & 1,356 & 1,626 & ------- & -------. \\
\hline & 20 & 0,875 & 1,373 & 1,642 & ------- & \\
\hline \multirow{4}{*}{$\mathbf{C}_{\mathbf{D}}$} & 4 & 0,0178 & 0,0267 & 0,0538 & -------- & \\
\hline & 7 & 0,0171 & 0,026 & 0,0522 & -------- & \\
\hline & 12 & 0,0164 & 0,0253 & 0,0512 & 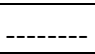 & - \\
\hline & 20 & 0,0157 & 0,0246 & 0,0507 & - ------ & - \\
\hline
\end{tabular}

Tablo 6. GOE 795 için $C_{L}$ ve $C_{D}$ değerleri

\begin{tabular}{|c|c|c|c|c|c|c|}
\hline \multicolumn{7}{|c|}{ GOE 795} \\
\hline & $\mathbf{V}(\mathbf{m} / \mathbf{s})$ & $\mathbf{0}^{\mathbf{o}}$ & $\mathbf{5}^{\mathbf{0}}$ & $10^{\circ}$ & $15^{\circ}$ & $20^{\circ}$ \\
\hline \multirow{4}{*}{$\mathbf{C}_{\mathbf{L}}$} & 4 & 0,223 & 0,748 & 0,115 & ------- & ------- \\
\hline & 7 & 0,227 & 0,758 & 0,119 & -------- & ------- \\
\hline & 12 & 0,2305 & 0,766 & 0,121 & ------- & ------- \\
\hline & 20 & 0,233 & 0,772 & 0,123 & ------- & ------- \\
\hline \multirow{4}{*}{$\mathrm{C}_{\mathbf{D}}$} & 4 & 0,0122 & 0,0153 & 0,0299 & ------- & ------- \\
\hline & 7 & 0,01094 & 0,01408 & 0,0272 & ------- & ------- \\
\hline & 12 & 0,01008 & 0,0132 & 0,025 & ------- & ------- \\
\hline & 20 & 0,0094 & 0,0123 & 0,0237 & ------- & 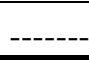 \\
\hline
\end{tabular}

\subsection{Kanat Performansları}

Bir kanat profilinin performans $1 C_{L} / C_{D}$ oranıyla ölçülmektedir. Şekil 6 ve Şekil $7 \quad \mathrm{C}_{\mathrm{L}} / \mathrm{C}_{\mathrm{D}}$ değerlerinin hücum açısı ile olan değişimlerini göstermiştir. Şekillerde performanslar en düşük rüzgar hızı $4 \mathrm{~m} / \mathrm{s}$ ve en yüksek rüzgar hızı olan 20 $\mathrm{m} / \mathrm{s}$ hız için verilmiştir.

Şekil $6 \& 7$ incelendiğinde FX-63-137 profili $0^{\circ} \leq \alpha$ $\leq 15^{\circ}$ hücum açıları arasında diğer profillere göre daha yüksek bir performans sahip olduğu görülmektedir. $\mathrm{Bu}$ profil $5^{\circ}$ hücum açısında ve 20 $\mathrm{m} / \mathrm{s}$ hizda maksimum olup değeri $\mathrm{C}_{\mathrm{L}} / \mathrm{C}_{\mathrm{D}}=61$ 'dir. EPPLER 58 her iki akıs hızında da $0^{\circ}<\alpha<5^{\circ}$ arası düşük hücum açılarında FX-63-137 kanat profili ile benzer performansa sahip olmuştur. $\mathrm{Bu}$ profilde en yüksek performansını $5^{\circ}$ hücum açısında ve $20 \mathrm{~m} / \mathrm{s}$ akış hızında $C_{\mathrm{L}} / \mathrm{C}_{\mathrm{D}}=56$ değeri ile almaktadır. GOE 795 profili $3^{\circ} \leq \alpha \leq 7^{\circ}$ arası hücum açılarında yüksek performans göstermiştir. GOE 795 kanadı ince bir kanat olduğundan hücum açısı ile olan değişimleri çok yüksek eğimlerde olmuştur. $\mathrm{Bu}$ kanat profili $5^{\circ}$ civarındaki hücum açılarında $\mathrm{FX}$ 63-137 kanat profiliyle benzer performansa sahip olmuştur. GOE 795 profili $\alpha>8^{\circ}$ 'den itibaren ki hücum açılarında ise diğer profillere göre en düşük performansa sahip olmuştur. Bu profilde en yüksek performansın $5^{\circ}$ hücum açısında ve $20 \mathrm{~m} / \mathrm{s}$ akış hızında $C_{L} / C_{D}=62$ değeri ile almıştır. FX-84-W218 profili ile selig S8036 profili üzerindeki her iki akış hızında da $\alpha \leq 8^{\circ}$ 'ye kadar diğer profillere göre performansları düşük kalmıştır fakat daha yüksek hücum açılarına doğru Selig S8036 performans1 FX-63-137 hariç diğer profillerden daha iyidir. $\mathrm{Bu}$ iki profilde en yüksek akış hızında maksimum performansları $C_{L} / C_{D}=42$ olmaktadır. Performansların hücum açısı ile olan değişimleri göz önüne alındığında tüm profillerin $3^{\circ}<\alpha<7^{\circ}$ arası hücum açılarında maksimum performansa sahip oldukları görülmektedir. Şekil 6\&7 incelendiğinde akış hızının artması $C_{L} / C_{D}$ değerlerini artırmıştır. En düşük hız ile en yüksek hız arasında performanslar değerlendirildiğinde hız artışıla birlikte tüm performans değerlerinin genelde \%15-25 arasında değişen bir artışa sahip oldukları olduğu görülmektedir. 


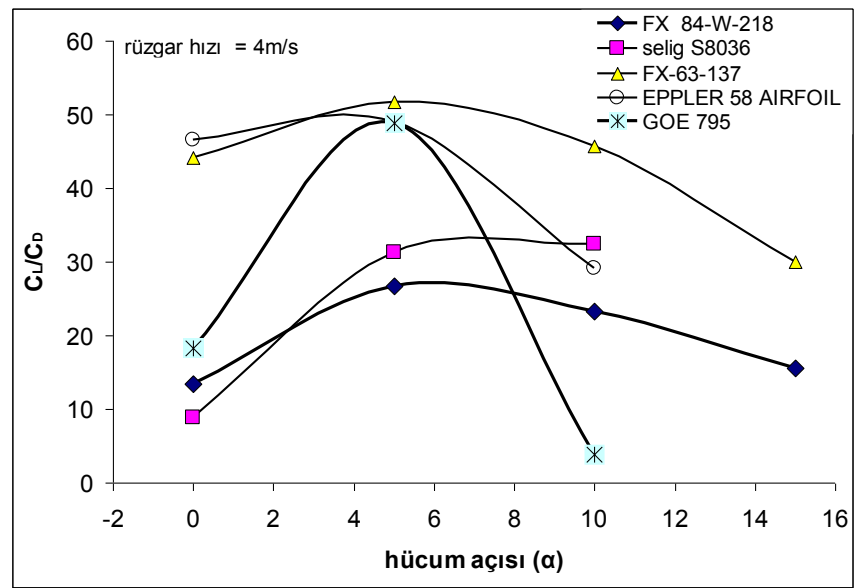

Şekil 6. $4 \mathrm{~m} / \mathrm{s}$ serbest akım hızında sayısal $C_{L} / C_{D}$ değerlerinin hücum açısı ile değişimleri

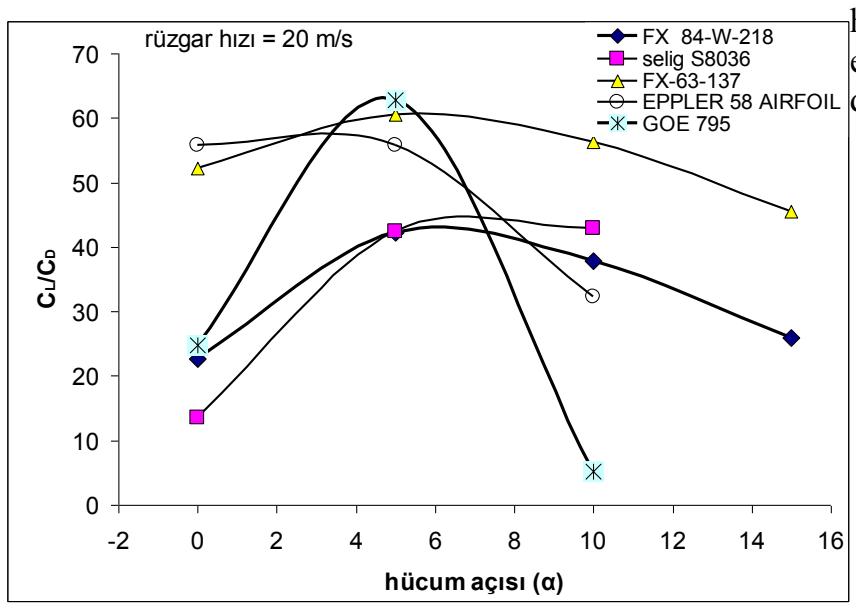

Şekil 7. $20 \mathrm{~m} / \mathrm{s}$ serbest akım hızında sayısal $C_{L} / C_{D}$ değerlerinin hücum açısı ile değişimleri

Shekil 8 kanat performansının akış hızı ile olan değişimini 0,5 ve 10 derece hücum açılarında göstermiştir. Burada $C_{L} / C_{D}$ değerlerinin akış hızı ile birlikte arttıkları görülmektedir. Burada performans artış1, eğimi her giderek azalan bir artıştır. Genel olarak performansların akış hızı ile olan değişimleri göz önünde bulundurulursa akış hızının artması ile birlikte performansların arttıkları ve farklı hücum açılarında ise bu artış eğimlerinin her profil için 6 biraz farklılaştığı görülebilmektedir.

Bu durum şekil 8 'de FX-63-137 için farklı hücum açılarında performansın hız ile olan değişim eğrileri ile gösterilmiştir. Şekil 8 'de 0,5 ve 10 derece hücum açılarında performans eğrileri benzer eğimde artarken 15 hücum derecesinde bu eğim daha yüksek olmuştur.
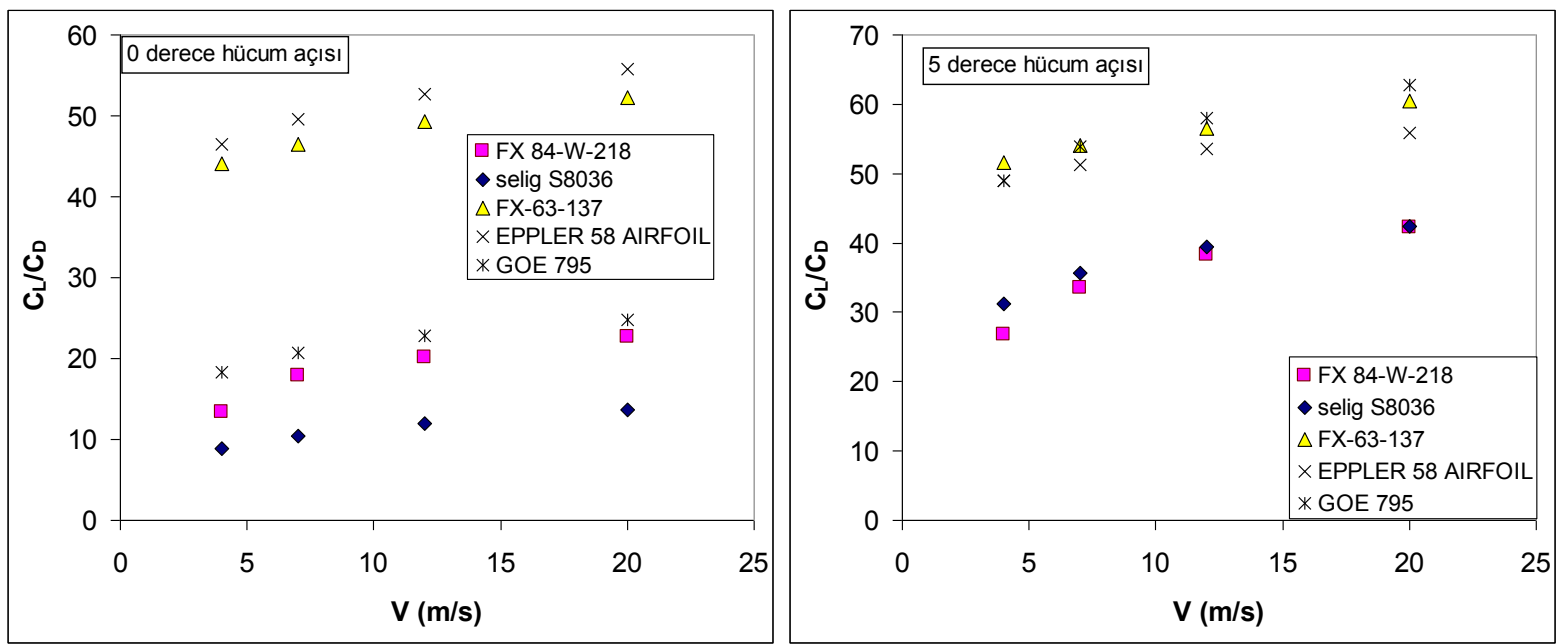

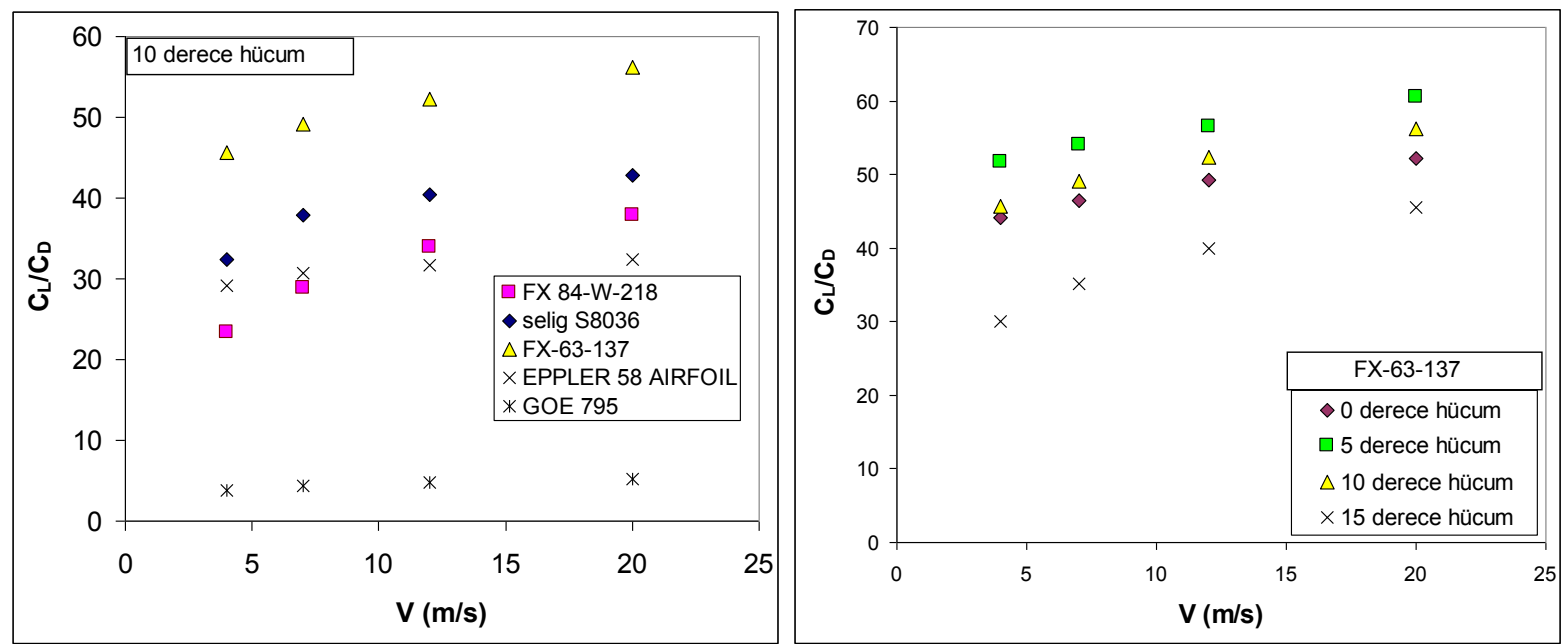

Şekil 8. 0,5 ve10 derece hücum açılarında $\mathrm{C}_{\mathrm{L}} / \mathrm{C}_{\mathrm{D}}$ değerlerinin serbest akım hızı ile değişimleri

\section{Sonuç ve Öneriler}

$\mathrm{Bu}$ çalışma, yüksek verimli rüzgar türbinleri oluşturmak için farklı kanatçık ailesinden seçilmiş beş ayrı kanat profilinin performanslarının sayısal olarak incelendiği bir konu olmuştur. Bu kanatlar, farklı hücum açılarında $\left(0^{\circ}, 5^{\circ}, 10^{\circ}, 15^{\circ}, 20^{\circ}\right)$ ve farklı rüzgar hızlarında $(4,7,12$ ve $20 \mathrm{~m} / \mathrm{s})$ performans yönünden test edilmişlerdir. Sayısal sonuçlardan kaldırma $\left(C_{L}\right)$, sürükleme $\left(C_{D}\right)$ ve basınç katsayılarının $\left(\mathrm{C}_{\mathrm{P}}\right)$ hücum açısıyla ve akış hızıyla olan değişimleri incelenmiştir ve sonuçlar ise aşağıda maddeler halinde verilmiştir.

Verilen bir hücum açısı için Rüzgar hızının artması tüm hücum açılarında $C_{L}$ değerlerini yükseltirken $\mathrm{C}_{\mathrm{D}}$ değerlerini de düşürmüştür. Kanat performansını gösteren $C_{L} / C_{D}$ oranı ise verilen bir hücum açısında hızın artmasıyla birlikte eğimi her giderek düşen bir artı̧̧1 göstermiştir. $C_{L} / C_{D}$ değerlerinin hücum açısıyla olan değişimleri doğrusal olmayan eğriler olmuştur. Tüm kanatlar için bu eğriler $3^{\circ}<\alpha<7^{\circ}$ arası hücum açılarında ve tüm akış hızlarını kapsayacak şekilde maksimum performans göstermişlerdir.

Tüm hücum açılarında FX-63-137 profili diğer profillere göre en yüksek performans değerlerine sahip olmuştur. EPPLER 58 profili düşük hücum açılarında $0^{\circ} \leq \alpha \leq 5^{\circ}$ FX-63-137 ile benzer yüksek bir performans göstermiştir. Ayrıca bu kanat $\alpha \leq 2^{\circ}$ hücum açılarında FX-63-137'den daha yüksek performans göstermiştir. GOE $7954^{\circ}<\alpha<6^{\circ}$ hücum açıları arasında FX-63-137 ile benzer yüksek bir performansa sahip olmuştur. Bu kanadın ince geometride olması performansının hücum açısı ile olan değişimlerini yüksek derecede etkilemiştir. Hücum açısı ile olan performans değişimleri çok yüksek eğimlerde olmuştur.
Kanat etrafındaki türbülanslı akış bölgesi daimi bir akış farzıyla RANS denklemleriyle çözülmüsşür. Düşük hücum açllarında RANS denklemlerle daimi akış sağlanırken yüksek hücum açılarında $\left(\alpha>15^{\circ}\right)$ türbülans akış bölgesi daimi akış özelliğinden uzaklaştığından sayısal değerlerde yakınsama problemlerine neden olmuştur. Bu nedenle yüksek hücum açılarındaki profil akışları daimi olmayan bir türbülanslı akıç çözümü gerektirmektedir.

\section{Kaynaklar}

[1] Amanullah Choudhry, Maziar Arjomandi, Richard Kelso, A study of long separation bubble on thick airfoils and its consequent effects, International Journal of Heat and Fluid Flow, Volume 52, April 2015, Pages 84-96.

[2] Bertagnolio F., Sorensen N.N. and Rasmussen F., "New Insight into the Flow around a Wind Turbine Airfoil Section" J. Solar Energy-Trans. ASME, 217(2), 214-222, 2005

[3] Dongli Ma, Yanping Zhao, Yuhang Qiao, Guanxiong $\mathrm{Li}$, "Effects of relative thickness on aerodynamic characteristics of airfoil at a low Reynolds number" Chinese Journal of Aeronautics Volume 28, Issue 4, August 2015, Pages 10031015

[4] Geissler W., Numerical Study of Buffet and Transonic Flutter on the NLR 7301 Airfoil, Aerospace Science and Technology, 7, 540-550, 2003

[5] Heyong Xu, Shilong Xing, Zhengyin Ye, "Numerical simulation of the effect of a co- flow jet on the wind turbine airfoil aerodynamic characteristics" Procedia Engineering 126 (2015) $706-710$

[6] K. Melih GÜLEREN ve Sinan DEMİR, "Rüzgar Türbinleri İçin Düşük Hücum Açılarında Farklı Kanat Profillerinin Performans Analizi" Is1 Bilimi ve Tekniği Dergisi, 31,2, 51-59, (2011) 
[7] Michael S. Selig and Bryan D. Mc Granahan, "Wind Tunnel Aerodynamic Tests of Six Airfoils for Use on Small Wind Turbines" National Renewable Energy Laboratory, Period of Performance: October 31, 2002-January 31

[8] Martinat G., Braza M., Hoarau Y. and Harran G., Turbulence Modelling of the Flow Past a Pitching (2008). NACA0012 Airfoil at 105 and 106 Reynolds Numbers, J. Fluids and Structures, 24, 1294-1303, 2008

[9] Nicolas Pellerin, Sébastien Leclaire, Marcelo Reggio (2015), "An implementation of the SpalartAllmaras turbulence model in a multi-domain lattice Boltzmann method for solving turbulent airfoil flows Computers \& Mathematics with Applications" Volume 70, Issue 12, December, Pages 3001-3018, (2015)

[10] P. A. Costa Rocha, H. H. Barbosa Rocha, F. O. Moura Carneiro, M. E. Vieira da Silva, C. Freitas de Andrade, "A case study on the calibration of the $k-\omega$ SST (shear stress transport) turbulence model for small scale wind turbines designed with cambered and symmetrical airfoils" Energy Volume 97, 15 February 2016, Pages 144-150

[11] Parezanovic V., Rasuo B. and Adzic M., "Design of Airfoils for Wind Turbine Blades", The French-Serbian European Summer University: Renewable Energy Sources and EnvironmentMultidisciplnary Aspect, 17-24 October 2006, Rnjačka Banja, Serbia

[12] Quan Wang, Jin Chen, Xiaoping Pang, Songlin Li, Xiaofeng Guo "A new direct design method for the medium thickness wind turbine airfoil" Journal of Fluids and Structures

Volume 43, November 2013, Pages 287-301

[13] Tangler J. T. and Somers D. M., "NREL Airfoil Families for HAWT" Proc. Wind Power '95, Washington D.C., ABD, 117-123, 1995

[14] Wei Zhang, Wan Cheng, Wei Gao, Adnan Qamar, Ravi Samtaney, "Geometrical effects on the airfoil flow separation and transition" Computers\&Fluids Volume 116, 15 August 2015, Pages 60-73

[15] http://m-

selig.ae.illinois.edu/ads/coord_database.html 